\title{
As recomendações e as soluções amistosas da Comissão Interamericana de Direitos Humanos: política, preferências e cumprimento ${ }^{1}$
}

\section{Adriano Sousa Costa}

Universidade de Brasília (UnB), Brasília, DF - Brasil

\section{João Roriz}

Universidade Federal de Goiás (UFGO), Goiânia, GO - Brasil

O artigo trata das recomendações e das soluções amistosas da Comissão Interamericana de Direitos Humanos e das respostas dos Estados a partir de uma ferramenta de avaliação de políticas públicas. Pressupondo a necessidade de problematizar o envolvimento da linguagem dos direitos humanos com os estudos de políticas públicas, o objetivo principal do texto é analisar as decisões da Comissão e a reação dos Estados a partir de preferências distintas dos atores envolvidos. $\mathrm{O}$ artigo considera as recomendações e soluções amistosas da Comissão não como um bloco monolítico sem distinções, mas como tipos variados que demandam políticas públicas diversas. Através da análise do relatório de 2017 da Comissão, em particular as suas ferramentas e o seu cumprimento por parte dos Estados, pode-se constatar que: (i) a Comissão Interamericana tem preferência por determinados tipos de ferramentas nos desenhos de soluções, (ii) os Estados também têm preferências por certos tipos de ferramentas, e (iii) tais preferências não coincidem com as da Comissão.

Palavras-chave: direitos humanos, Comissão Interamericana de Direitos Humanos, ferramentas de política pública

${ }^{1}$ Este trabalho foi financiado pelo Programa Primeiros Projetos da Fundação de Amparo à Pesquisa do Estado de Goiás (FAPEG). 


\section{Las recomendaciones y soluciones amigables de la Comisión Interamericana de Derechos Humanos: política, preferencias y cumplimiento}

El artículo aborda las recomendaciones y soluciones amigables de la Comisión Interamericana de Derechos Humanos y las respuestas de los Estados basadas en una herramienta para evaluar las políticas públicas. Asumiendo la necesidad de problematizar la participación del lenguaje de los derechos humanos en los estudios de política pública, el objetivo principal del texto es analizar las decisiones de la Comisión y la reacción de los Estados en función de las diferentes preferencias de los actores. El artículo considera las recomendaciones y soluciones amigables de la Comisión, no como un bloque monolítico sin distinciones, sino como tipos variados que exigen políticas públicas diferentes. A través del análisis del informe de 2017 de la Comisión, en particular sus herramientas y el cumplimiento por parte de los Estados, se puede ver que: (i) la Comisión Interamericana tiene preferencia sobre ciertos tipos de herramientas en el diseño de las soluciones, (ii) Los Estados también tienen preferencias para ciertos tipos de herramientas, y (iii) esas preferencias no coinciden con las de la Comisión.

Palabras clave: derechos humanos, Comisión Interamericana de Derechos Humanos, herramientas de política pública

\section{The recommendation and friendly solutions of the Inter-American Commission on Human Rights: policy, preferences and compliance}

The article deals with the recommendations and friendly settlements of the Inter-American Commission on Human Rights and the responses of states based on public policies tools. Assuming the need to problematize the relation between the language of human rights with public policy studies, the main objective of the text is to analyze the decisions of the Commission and the States' reactions based on different preferences of the actors involved. The article considers the Commission's recommendations not as a monolithic block without distinctions, but as varied types that demand diverse public policies. Through analysis of the Commission's 2017 report, in particular its tools and compliance by States, the research shows that: (i) the Inter-American Commission has preferences for certain types of tools when drawing its solutions, (ii) states also has preferences for certain types of tools, and (iii) such preferences do not coincide with the Commission's.

Keywords: human rights, Inter-American Commission on Human Rights public policies 


\section{Introdução}

É ampla a literatura que lida com a efetividade das decisões de organizações internacionais. Parte significativa dos estudos mais recentes se dedica a analisar como e por que um Estado incorpora normas ou obedece decisões de organizações internacionais que poderiam ser consideradas como limites às suas ações ou mesmo à sua soberania. As variáveis explicativas são diversas: enquanto alguns estudiosos centram suas análises nos objetivos de política externa (GOOdMAN, 2000; HeYNS; VILJOEN, 2001), ou nos interesses das grandes potências (BRYSK, 1994), outros buscam explicações domésticas, como a natureza dos regimes políticos (HAFNeR-BURTON; TSUTSUI; MEYER, 2008), ou ainda há aqueles que se voltam às especificidades de um tratado (HATHAWAY, 2007; COLE, 2005).

Em relação às obrigações de direitos humanos, duas grandes correntes dos estudos de relações internacionais ${ }^{2}$ oferecem explicações sobre as razões que levam Estados a cumprir com elas. Há estudos que privilegiam certa "lógica de consequências": os Estados cumprem com normas e decisões sobre direitos humanos porque há incentivos para tal. Para a cientista política Beth Simmons (2009), por exemplo, as melhores variáveis explicativas do comportamento de Estados em relação à observância de normas de direitos humanos são aquelas de cunho doméstico, como o tipo de governo ou de regime político, partidos políticos, sistema judicial, arranjo institucional de ratificação etc. Outros estudos, geralmente da corrente construtivista, ressaltam uma "lógica da adequação": para eles, os Estados cumprem normas porquanto é adequado ao convívio social no plano internacional. No livro organizado por Risse, Ropp e Sikkink (2014) subsiste a tese de que é na interação e por pressão de atores externos que Estados mais resistentes acabam fazendo concessões e incorporando normas de direitos humanos em seus ordenamentos jurídicos.

\footnotetext{
${ }^{2}$ Não queremos com isso afirmar que há apenas duas vertentes teóricas da literatura de relações internacionais dedicadas ao tema dos direitos humanos. Pelo contrário, há textos de correntes diversas sobre o assunto; todavia, o liberalismo e o construtivismo aqui ressaltados têm dominado as publicações no tema. Os principais textos insistem em excluir outras abordagens, principalmente as críticas ao positivismo e ao racionalismo, o que demonstra a limitação epistemológica da literatura. Para alguns trabalhos fora do mainstream, ver: Yamato (2014), Mutua (2002), Bernardi (2017) e Calabria (2017).
} 
Os estudos sobre a observância ${ }^{3}$ de direitos humanos refletem as duas correntes mencionadas. A vertente liberal desloca a unidade de análise para o plano doméstico. Para entender como os Estados seguem determinadas normas (e como o fazem) em detrimento de outras, Hillebrecht (2012) sugere investigar os microprocessos políticos de atores como Executivo, Legislativo, Judiciário, sociedade civil e ONGs, suas articulações, coalizões, interesses e incentivos. Próximos do construtivismo, mas não muito distantes dos liberais, Dancy e Sikkink (2012) confirmam a validade explicativa do modelo centrado nas questões domésticas, mas entendem que ele não reconhece o papel que instituições internacionais exercem ao facilitar os procedimentos internos de um Estado. Aparentemente, tais correntes têm mais consensos que dissensos, e seus diálogos estão centrados em qual plano se enfatiza, o doméstico ou o internacional. Parte significativa do atual debate na área se restringe a discussões baseadas em modelos estatísticos como, por exemplo, se os Estados que mais ratificam tratados de direitos humanos são mais ou menos propensos a violar direitos humanos. ${ }^{4}$

Tais estudos estão centrados no comportamento dos Estados e, em geral, assumem as recomendações das instituições internacionais de forma cônsona, obscurecendo as preferências dessas organizações. Um dos poucos trabalhos que propõem uma abordagem mais complexa a partir do tipo de recomendação de uma organização internacional é o da cientista política Courtney Hillebrecht, da Universidade de Nebraska-Lincoln. Em um texto que trata da mensuração da observância das decisões de tribunais de direitos humanos, Hillebrecht (2009) avança um esquema que leva em consideração as "medidas individuais" (aquelas direcionadas aos indivíduos que supostamente sofreram uma violação, como a abertura de investigações) e as "reparações financeiras" para se chegar a um índice de observância. Este é então comparado com as "medidas de não repetição" (geralmente medidas administrativas ou legislativas) implementadas por parte do Estado, para enfim se ter o que ela denomina como "índice agregado de observância". Seu modelo estatístico,

\footnotetext{
${ }^{3}$ Em inglês se usa o termo 'compliance', de tradução espinhosa para o português, pois a natureza da obrigação pode ter mais de um sentido. Pode significar tanto um cumprimento rígido e estrito de uma norma jurídica ou uma conformidade menos rígida, com um caráter mais de consideração ao invés de obrigatoriedade. Optamos pelo vernáculo 'observância', que tem as seguintes definições: “(i) ato ou efeito de observar; (ii) execução, cumprimento de regra ou lei” (Larousse Dicionário da língua portuguesa/ Coordenação Diego Rodrigo e Fernando Nuno. 2a ed., São Paulo: Larousse do Brasil, 2008).

${ }^{4} \mathrm{~A}$ correlação negativa entre a ratificação de tratados de direitos humanos e sua observância é apontada por Hafner-Burton, Tsutsui e Meyer (2008) e por Hathaway (2002). Outros apresentaram novos dados empíricos para contestar tal correlação, como Dancy e Sikkink (2012) e Fariss (2018).
} 
no entanto, ainda oferece pouco espaço para a diversidade das decisões das instituições internacionais e, como consequência, para se entender as reações dos Estados frente a tipos distintos de decisões.

Neste artigo, propomos analisar algumas das soluções de casos oriundas da Comissão Interamericana de Direitos Humanos (doravante "CIDH" ou "Comissão") e as respostas dos Estados à luz de um instrumental taxonômico das ferramentas costumeiramente utilizadas. Consideramos que ainda há poucos estudos que avaliam o cumprimento de normas e decisões sobre direitos humanos a partir de sua diversidade, ou seja, considerando as soluções de caso na $\mathrm{CIDH}$ não como um bloco monolótico sem distinções, mas como tipos variados quanto às suas exigências. Para realizarmos a pesquisa, utilizamos como base os desenhos das soluções de casos no âmbito da CIDH, mencionadas no relatório de seguimento de casos do ano de 2017, sejam essas soluções materializadas em acordos ou mesmo em recomendações da CIDH. A diferença entre essas duas formas de solução de casos é que na amistosa (acordos) são as próprias partes que escolhem as ferramentas que vão compor o desenho da política pública, não havendo ingerência direta da CIDH nessa construção; já na solução de mérito, também chamada de recomendação, é a CIDH, após constatar a não realização de acordo entre as partes envolvidas, que escolhe sozinha as ferramentas que vão compor o desenho da solução. Cabe ao Estado, após o acordo ou a recomendação, deliberar se cumpre (ou não) o desenho da solução do caso que lhes é encaminhado.

Enfim, é com base nesse ferramental de políticas públicas (sejam insertas em desenhos amistosos ou em recomendações) que foi possível classificar as ferramentas (ou medidas) de políticas públicas em gêneros e espécies variados. Optamos por esse caminho porquanto ele pode revelar as preferências das instituições e das próprias partes envolvidas na contenda por determinados tipos de ferramentas, assim como as diferentes respostas dos Estados quanto ao seu cumprimento. É revelador, por exemplo, que uma ferramenta, como a promoção da isenção de tributos em face das indenizações pagas, tenha um índice de cumprimento de mais de $90 \%$ por parte dos Estados, enquanto que a medida de dar início ou prosseguimento à persecução penal em face das violações seja cumprida menos de $1 \%$ das vezes - e que essa última seja a segunda medida mais utilizada no âmbito da Comissão. 
Entendemos ser necessário problematizar o envolvimento da linguagem dos direitos humanos com os estudos de políticas públicas, tanto em termos teoréticos quanto empíricos. A instrumentalização dos direitos humanos tem conseguido deslocar os debates sobre os usos políticos dessa linguagem em contextos diferentes, as preferências camufladas dos atores que a usam e as consequências dessa instrumentalização. A construção liberal da defesa dos "direitos levados a sério" direcionou uma leitura que propulsiona direitos (individuais) como "trunfos" capazes de limitar (ou mesmo superar) políticas (DWORKIN, 2011). Neste esquema, o lugar de autoridade de quem reivindica o cumprimento de um direito é diferente daquele que defende uma boa política assumindo preferências. Em um cenário crescente onde as escolhas (não assumidas) do movimento de desformalização de regras jurídicas resultam em uma argumentação propositiva baseada em princípios abstratos (MANGABEIRA UNGER, 1977), entendemos ser necessário elucidar as preferências (políticas) de quem 'fala direitos humanos'.

Com tais inquietações e pressupostos de fundo, estamos preocupados, neste texto, com um trabalho de cunho mais empírico. Analisamos o relatório de 2017 da Comissão Interamericana de Direitos Humanos, em particular as suas ferramentas e o seu cumprimento por parte dos Estados. Na próxima seção, apresentamos brevemente a instituição em apreço e seu desenho institucional em relação às medidas que costumam compor os desenhos das soluções. Em seguida, mostramos como as medidas que constam nas soluções de casos, construídas no âmbito da $\mathrm{CIDH}$, podem ser enquadradas a partir de um modelo de classificação de ferramentas de políticas públicas. Por fim, com base no relatório de 2017, analisamos os números das ferramentas contidas nos desenhos de soluções de casos, no âmbito da Comissão, e o respectivo cumprimento por parte dos Estados.

\section{A Comissão Interamericana de Direito Humanos e a forma de solução de casos}

A Comissão Interamericana de Direitos Humanos foi estabelecida em 1959, como um órgão autônomo da Organização dos Estados Americanos (OEA). Inicialmente pensada como um grupo de estudos sobre direitos humanos, seus fundadores não previram o apelo 
político que a instituição teria. Interpretações diversas apontam para o desenvolvimento do desenho institucional e político da CIDH. Alguns interpretam que a chegada de diversas petições sobre violações de direitos humanos em países nas Américas propulsionou o entendimento entre os comissionários de que, a fim de promover direitos humanos, a CIDH deveria ter uma postura de proteção (e.g., MEDINA, 1990), deixando de ser um órgão apenas de estudos. Outros localizam no jogo geopolítico das relações EUA-América Latina na Guerra Fria o desenvolvimento da Comissão (e.g., ENGSTRom, 2016). De qualquer forma, a partir de 1965, a CIDH começou a examinar o cumprimento de normas de direitos humanos nos países membros da OEA. Sua prática de investigações e publicações de pretensas violações passou a ser a regra, o que foi referendado com uma emenda à Carta da OEA em 1967.

A CIDH obteve uma base jurídica mais firme a partir da Convenção Americana sobre Direitos Humanos, de 1969. A partir desse documento, a Comissão passou a desempenhar um duplo papel. Ela manteve seu status de órgão da OEA, responsável pela promoção e proteção de direitos humanos nas Américas. Depois da Convenção de 1969 ter entrado em vigor em 1978, a CIDH também supervisiona direitos humanos para os países que ratificaram a Convenção e pode levar casos à Corte Interamericana de Direitos Humanos contra Estados. Nem a Comissão nem a Corte lidam com responsabilidade de indivíduos por violações de direitos humanos, apenas com a responsabilidade de Estados. Enquanto a Corte só julga casos dos vinte Estados americanos que aceitaram sua jurisdição, a CIDH lida com situações dos trinta e cinco membros da OEA.

ACIDH agrupa suas atividades em três: sistema de petição individual, monitoramento da situação de direitos humanos nos Estados membros e promoção de estudos em áreas temáticas. Nosso interesse neste texto reside na função considerada "semi-judicial" da Comissão, ou seja, os casos que são levados a ela. Esses podem ser iniciados por indivíduos, grupos de pessoas ou ONGs reconhecidas nos Estados membros da OEA, ou mesmo pela própria CIDH. Após receber a comunicação, a CIDH determina a admissibilidade, tal como disposto nos artigos 46 e 47 da Convenção de 1969. Ela pode requerer informações ao Estado envolvido na suposta violação, assim como pode, com a permissão do Estado, conduzir investigações in loco. 
Após a decisão sobre admissibilidade, dois são os possíveis resultados para os casos na $\mathrm{CIDH}$, segundo o disposto na Convenção de 1969. A CIDH nomeia o primeiro como "seguimento de solução amistosa", tal como disposto no artigo 49, e o segundo como "seguimento de recomendações ou informes", descrito no artigo 51. Na solução amistosa, a CIDH se coloca à disposição das partes para se chegar a um entendimento. Caso essa não seja uma opção, os comissionários redigem o primeiro relatório, que é confidencial, com a exposição do ocorrido e com recomendações ao Estado. Se, após três meses, o caso não for enviado à Corte, ou não for solucionado de forma amistosa, os comissionários podem escrever um segundo relatório com suas conclusões e recomendações ao Estado em questão, assim como um tempo limite para o Estado cumprir com suas recomendações. Após esse prazo, a Comissão decide sobre o cumprimento do Estado, se publica sua decisão e se o caso é enviado à Corte. No descumprimento do segundo relatório e na ausência de caso na Corte, a CIDH encaminha seu relatório à Assembleia Geral da OEA para que esta organização busque pressionar o Estado em questão.

A capacidade da CIDH de fazer recomendações aos Estados membros da OEA está listada no artigo 41 da Convenção de 19695. No texto: “(b) formular recomendações aos governos dos Estados membros, quando o considerar conveniente, no sentido de que adotem medidas progressivas em prol dos direitos humanos no âmbito de suas leis internas e seus preceitos constitucionais, bem como disposições apropriadas para promover o devido respeito a esses direitos". O dispositivo não dá maiores diretrizes sobre como a Comissão deve proceder na elaboração e verificação das suas recomendações, o que Ihe confere significativa discricionariedade. Os limites textuais são módicos e se restringiriam a interpretações das palavras "conveniente", "progressivas" e "apropriadas" contidas no dispositivo. As recomendações variam muito, em relação às instituições domésticas envolvidas, suas naturezas e funções, alcances e custos. Podem ir de declarações públicas

\footnotetext{
5 “Art. 41. A Comissão tem a função principal de promover a observância e a defesa dos direitos humanos e, no exercício do seu mandato, tem as seguintes funções e atribuições: a. estimular a consciência dos direitos humanos nos povos da América; b. (...); c. preparar os estudos ou relatórios que considerar convenientes para o desempenho de suas funções; d. solicitar aos governos dos Estados membros que lhe proporcionem informações sobre as medidas que adotarem em matéria de direitos humanos; e. atender às consultas que, por meio da Secretaria-Geral da Organização dos Estados Americanos, Ihe formularem os Estados membros sobre questões relacionadas com os direitos humanos e, dentro de suas possibilidades, prestar-Ihes o assessoramento que eles Ihe solicitarem; f. atuar com respeito às petições e outras comunicações, no exercício de sua autoridade, de conformidade com o disposto nos artigos 44 a 51 desta Convenção; e g. apresentar um relatório anual à Assembleia Geral da Organização dos Estados Americanos."
} 
em honra ao nome da vítima a solicitações de alterações na legislação ou de criação de tribunais ad hoc para lidar com indenizações.

É importante ressaltar que as soluções da CIDH (sejam amistosas ou recomendações) não são consideradas obrigatórias aos Estados membros, ao contrário dos julgamentos da Corte Interamericana. Ainda que a CIDH considere o cumprimento integral de suas decisões um "elemento indispensável" (CIDH, 2017, p. 105) para assegurar os direitos humanos nas Américas, elas têm efeito de recomendação. Ainda assim, a instituição tem sido crescentemente demandada. As petições recebidas pela CIDH têm aumentado: 1.325 em 2006, 1.936 em 2012, e 2.494 em 2017.

Desde 2001, a CIDH publica em seus relatórios oficiais uma seção sobre cumprimento. A fim de averiguar o cumprimento de suas decisões, a Comissão solicita informações aos Estados membros, celebra audiências e adota outras medidas que considerar oportunas. ${ }^{6}$ Para confecção do relatório de 2017, a Comissão recebeu informações dos países membros até 3 de novembro de 2017,7 mas a decisão final sobre o status das soluções de caso foi decidida pelos comissionários. No relatório final há a consideração de que algumas de suas soluções (e das respectivas ferramentas) são de implementação gradual e requerem tempo. A própria Comissão tem uma categorização de observância: (i) "cumprimento total", (ii) "cumprimento parcial", e (iii) "pendentes de cumprimento". ${ }^{8}$ Hillebrecht (2009) critica esse sistema, pois em sua opinião ele acaba estimulando os Estados a observarem apenas uma parte menor ou menos custosa dos desenhos das soluções, uma vez que o implemento mínimo já o tiraria da categoria de "pendentes" para a outra de "cumprimento parcial".

O relatório consultado lista o total de 207 casos na CIDH. Há certo equilíbrio entre as duas formas de solução de casos na CIDH: 109 tiveram o "seguimento de solução amistosa", e 98 o "seguimento de recomendações ou informes". Quando se considera o

\footnotetext{
${ }^{6}$ De acordo com o art. 41 da Convenção Americana e com o art. 48 do Estatuto da Comissão.

${ }^{7}$ O relatório versa sobre todos os casos que tramitam ou tramitaram na CIDH de 2000 a 2017.

${ }^{8}$ A Comissão considera "cumprimento total" as soluções de caso que "o Estado iniciou e concluiu satisfatoriamente os trâmites para o seu cumprimento", "cumprimento parcial" aquelas que o Estado cumpriu "somente alguma(s) recomendações" ou aquelas que "cumpriu de maneira incompleta", e finalmente as "pendentes de cumprimento" aquelas que "não há nenhuma gestão iniciada para tal fim", que o Estado "indicou que não irá cumprir" ou que o "Estado não informou" à CIDH (CIDH, 2017, p. 106).
} 
grau de cumprimento, no entanto, há diferenças significativas, mas não é muita surpresa que os Estados cumprem mais as soluções amistosas. Dos casos que ostentam o status 'cumprido totalmente', 40 são amistosos e 8 tiveram seguimento por recomendações e informes. Dentre os 'parcialmente cumpridos', 67 são amistosos e 59 por recomendações e informes. Por fim, nos casos 'pendentes de cumprimento', apenas 2 são amistosos e em 31 tiveram recomendações e informes (CIDH, 2017). Esse é o único sistema próprio da CIDH que informa sobre o cumprimento de suas soluções de caso. A capacidade do sistema de transparecer suas preferências e quais tipos de medidas os Estados cumprem são extremamente limitados.

\section{Um conjunto de ferramentas para analisar as formas de solução de casos na Comissão Interamericana}

A fim de oferecer um quadro mais complexo e interessante sobre as ferramentas de políticas públicas utilizadas no âmbito da $\mathrm{CIDH}$, optamos pelo uso dos parâmetros do construto teorético de Christopher Hood, professor na Universidade de Oxford. Sua obra The Tools of Government foi publicada pela primeira vez em 1983, e em 2007 foi atualizada em coautoria com Helen Margetts, também de Oxford. Consideraremos o aporte de Hood na medida em que ele fornece um olhar para as práticas de uma instituição a partir de um instrumental capaz de identificar suas classes, variações e finalidades. Para Hood (1983; 2007), o Estado é uma forma de controle da sociedade, especificamente uma entidade que observa e obtém informações, e também que age com base em tal conhecimento. Ele propõe então um "toolkit" para se analisar um Estado através dos recursos que ele tem à sua disposição.

Para Hood (1983; 2007), os quatro recursos básicos de um Estado seriam: (i) nodalidade, (ii) autoridade, (iii) tesouro, e (iv) organização (o que ele chama de 'modelo NATO', por conta do seu acrônimo). Na opinião de Howlett, Ramesh e Perl (2013, p. 129), essa taxonomia "simples e poderosa" propõe que "todas as ferramentas políticas usam uma de quatro categorias amplas de recursos de governo ou de controle". Ainda segundo tais autores, governantes usam tais ferramentas para manipular os atores políticos, por exemplo, controlando informações ou dinheiro, utilizando seu pessoal e expertise 
para desenvolver atividades ou mesmo usando seu monopólio legítimo do uso da força (Howlett; RAmesh; Perl, 2013).

Optamos neste artigo pela utilização do modelo de Hood (1983; 2007) para analisar as soluções de casos ocorridas no âmbito da CIDH. Entendemos que o emprego desse esquema pode auxiliar na compreensão das mais variadas ferramentas utilizadas nesse contexto, agrupando-as em categorias, e pode também demonstrar quais tipos de recomendações têm sido propostas, possivelmente amparando comparações. Obviamente, o modelo NATO também traz limitações, uma vez que foi pensado para considerar um governo doméstico, não as imposições de um organismo internacional como a CIDH. Todavia, entendemos que tal analogia tem mais benefícios e potencialidades do que riscos para a análise que pretendemos. Também optamos pela inclusão de um outro gênero (não elencado por Hood) para abarcar a medida de outorga parcial e genérica do desenho da política pública ao Estado-violador, no qual o Estado é livre para adotar as ferramentas de política que julgar suficientes para evitar violações futuras e semelhantes.

Passamos então para a definição de cada uma das ferramentas propostas no modelo. A 'nodalidade' representa a capacidade da autoridade pública de ser um nódulo, i.e., um ponto focal de informações em uma rede social (HooD, 1983; 2007). Alguns exemplos seriam as campanhas publicitárias, a exortação (ou persuasão), o benchmarking, as comissões e os inquéritos (Howlett; RAMESH; PeRL, 2013). Para Hood (1983; 2007), essa ferramenta tem relação com o posicionamento central de um governo para armazenar e usar informações em relação à sociedade. Consideramos que as seguintes ferramentas da CIDH lidam em alguma medida com informação (vide Tabela 01): publicação do resultado na imprensa nacional e/ou local (N.1); declaração pública em honra ao nome da vítima e/ ou seus familiares (N.2); ${ }^{9}$ reconhecimento da responsabilidade internacional do Estado (N.3); adequação de conteúdo em grades curriculares de cursos de formação profissional

\footnotetext{
${ }^{9}$ Classificamos dentro destas algumas medidas que, além de envolver informação, também trazem medidas com caráter de não-repetição e de custos econômicos. Por exemplo: a construção de um "museu da verdade" é classificada como ferramenta N.2, por mais que tenha custos para o Estado. Contudo, consideramos que a finalidade específica da recomendação diz mais respeito à difusão de informações do que ao custo da empreitada.
} 
(N.4); promoção da capacitação de agentes públicos (N.5):;10 produção de informações (N.6); ${ }^{11}$ e, difusão de informações (N.7).

Por 'autoridade', Hood (1983; 2007) entende os poderes legais ou oficiais, ou seja, os poderes de oficialmente demandar, proibir, garantir ou abjudicar. Autoridade seria "tradicionalmente vista como uma das propriedades definidoras do governo, embora sua origem, base e nível possam variar" (Hood, 1983, p. 5). Suas ferramentas são marcadas por certo contorno impositivo, um poder de mando para a realização de algo. O autor não discute as origens dessa autoridade, mas seus usos. Alguns exemplos seriam ações que visam regulamentar, licenciar e autorizar determinadas práticas (HOWLETT; RAMESH; PERL, 2013). Categorizamos as seguintes ferramentas a partir do conteúdo das soluções de casos ocorridos na CIDH: prestação de informações ou realização de determinados atos administrativos (A.1);12 restrição de recursos judiciais contra sentenças favoráveis às vítimas (A.2); ${ }^{13}$ criação de condições para recursos das vítimas (A.3); ${ }^{14}$ admissão ou readmissão de pessoas em cargos, empregos e funções (A.4); ${ }^{15}$ iniciar ou dar prosseguimento a persecuções penais $(\mathrm{A} .5) ;{ }^{16}$ regulamentação de leis ou propositura de alterações administrativas (A.6); criação, regulamentação ou reforma de leis (A.7); ${ }^{17}$

\footnotetext{
${ }^{10}$ As ferramentas N.4 e N.5 envolvem práticas burocráticas direcionadas a grupos específicos, como modificação em grades curriculares em cursos de formação e a capacitação de agentes públicos - incluindo a formação de policiais. A ideia principal é que tais atores funcionem como difusores de informações relacionadas a direitos humanos.

${ }^{11}$ A ferramenta N.6 envolve a produção de informações, por meio de estudos ou de grupos de trabalho, tais como as Comissões da Verdade ou grupos engendrados para a produção de informações voltadas a subsidiar eventuais alterações legislativas.
}

${ }^{12}$ Nesta ferramenta, é exigido que o Estado (ou particulares) preste determinadas informações, ou realize algum ato administrativo, como a entrega de documentos à vítima, a realização de busca por corpos de pessoas desaparecidas e desativação de recintos usados para violações de direitos humanos.

${ }^{13}$ A ferramenta A.2 traz limites à atuação postulatória (ou à recursal) do Estado em face dos interesses da vítima da violação. Aqui a ferramenta visa a manietar os órgãos do Estado frente ao seu direito de acesso à Justiça, bem como de busca do grau recursal para a reforma de uma decisão que tenha sido desfavorável aos interesses do Estado-violador.

${ }^{14}$ Nesta ferramenta o Estado deve agir no sentido de viabilizar a impetração de recursos para a reforma de uma decisão desfavorável ao direito da vítima da violação ou dos peticionários, o que pode significar até um novo julgamento.

${ }^{15} \mathrm{Na}$ ferramenta A.4 o governante é obrigado a readmitir pessoas que foram indevidamente desligadas de suas atividades, sendo o Estado obrigado, inclusive, a restaurar todas as vantagens relacionadas ao status quo ante.

${ }^{16}$ Por esta ferramenta cabe ao governante ordenar a investigação dos fatos que deram origem à denúncia internacional, além de, se for o caso, buscar a punição em face da leniência de agentes públicos que não promoveram tais investigações internamente a contento.

${ }^{17}$ As ferramentas A.6 e A.7 dizem respeito à demanda por criação, alteração, revogação ou implementação de alguma lei face uma obrigação internacional. 
alteração de penas (A.8); ${ }^{18}$ abstenção por parte de instituições internas de medidas que possam prejudicar as vítimas (A.9); $;^{19}$ elaboração de políticas públicas diversas (A.10). ${ }^{20}$

Hood $(1983 ; 2007)$ classifica como 'tesouro' a posse de bens fungíveis por parte do governo, principalmente dinheiro. ${ }^{21} \mathrm{Na}$ sua descrição, tesouro é o que permite ao governo práticas diversas, de comercializar a compra de apoio. Todas as ferramentas certamente impõem gastos, assim é preciso saber diferenciar quando o dinheiro é o substrato principal da política pública ou ele é um mero meio para atingimento de outros objetivos. ${ }^{22}$ Dentre as medidas da $\mathrm{CIDH}$, classificamos as seguintes como tesouro: indenização imediata (T.1) ou parcelada (T.2); ${ }^{23}$ pagamento de pensão por morte (T.3); isenção de tributos (T.4); criação de tribunais ad hoc para lidar com indenizações (T.5); pagamento de haveres oriundos da violação (T.6); concessão de aposentadorias (T.7); fundos sociais para a vítima (T.8); aplicação de multas (T.9).

Por fim, o modelo de Hood (1983, p. 72) traz também as ferramentas de 'organização', um "rótulo para um estoque de terrenos, edifícios e equipamentos, e uma coleção de indivíduos com quaisquer habilidades que eles possam ter, em posse direta do governo". Organização tem um sentido de capacidade própria do Estado de conduzir ações sem precisar de outrem (como mercenários, por exemplo). Elas têm como

\footnotetext{
${ }^{18}$ A ferramenta determina que os poderes constituídos nacionais imponham aos órgãos ou às instituições internas a necessária comutação, o abrandamento ou a isenção de pena (ou de seus efeitos) em face de determinada pessoa.

${ }^{19}$ A determinação dessa ferramenta é para que os Poderes constituídos nacionais obriguem aos órgãos ou às instituições internas a se absterem de prejudicar a vítima de alguma forma, evitando-se retaliações pessoais em face de o peticionário ter buscado as vias internacionais.
}

${ }^{20} \mathrm{~A}$ ferramenta A.10 envolve aquelas medidas nas quais a $\mathrm{CIDH}$ ou as partes especificam o objeto da política pública a ser desenvolvida, bem como sobre as possíveis ferramentas a serem utilizadas para concretizar essa mandamento.

${ }^{21}$ É necessário esclarecer que, por mais que a maioria das ferramentas pressuponha dispêndio de valores, nem por isso devem ser elas encaixadas nessa categoria. Diferentemente das outras categorias (que também custam dinheiro para serem implementadas), os recursos financeiros exercem aqui o papel de vetor principal da ferramenta.

${ }_{22}$ Por exemplo, a CIDH recomenda a um Estado a implementação de um curso de aperfeiçoamento para policiais, em face da constatação de que são reiterados os atos de violência por eles praticados. Apesar dos custos que envolvem a implementação de tal recomendação, o que mais importa nessa ferramenta não é o dinheiro, mas, sim, o convencimento das pessoas por meio da informação. A informação é que vai ser utilizada como objeto principal para as mudanças almejadas, e não gastos envolvidos nela. Nesse exemplo, consideramos a ferramenta no rol das de 'nodalidade'.

${ }^{23}$ A ferramenta T.1 se diferencia da ferramenta T.2 somente pelo fato de que nesta a indenização dever ser paga parceladamente, enquanto naquela se paga a reparação em uma só parcela. Essa diferença tem relevância prática: como os pagamentos na ferramenta T.2 são diferidos, o status de cumprimento total do caso é postergado em face da própria natureza da medida. 
objetos principais a criação de órgãos e instituições públicas, a reorganização da máquina pública (administração direta, indireta e paraestatal), bem como a criação de instituições eminentemente privadas, desde que tais atos de engenharia administrativa sejam voltados para o atingimento dos objetivos traçados tomadores de decisões. Usamos três categorias para enquadrar as ferramentas de organização: criação de órgãos ou setores de investigação, monitoramento ou prevenção (0.1); criação de cargos a serem preenchidos por concurso público (0.2); e, readequação, fortalecimento ou reformulação de órgãos, servidores, instituições e setores (0.3).

Incluímos, por fim, um gênero, contido de uma única ferramenta, na qual a CIDH solicita que o Estado adote, por outorga, "medidas necessárias" para evitar a repetição da violação, ${ }^{24}$ sem, no entanto, especificar quais seriam tais medidas. Denominamos tal gênero e medida como sendo "genérica de não repetição" (NR).

\section{Dados sobre o índice de cumprimento das ferramentas}

A confecção da Tabela 1 abaixo foi feita da seguinte forma. Em primeiro lugar, categorizamos cada um dos 207 casos listados no relatório da Comissão de 2017 a partir do modelo de Hood (1983; 2007). Como alguns pontos da solução de caso dizem respeito a ações que poderiam ser classificadas em mais de uma categoria, não consideramos nesse caso apenas uma ferramenta, mas sim quantas ferramentas tinham relação com cada ação em apreço. Por exemplo, no caso 12.418, a CIDH solicitou à Jamaica que realizasse uma investigação cabal sobre uma violação, mas que, para que isso acontecesse, era essencial que houvesse uma alteração legislativa prévia permitindo essa investigação. ${ }^{25}$ Dessa forma, consideramos a presença tanto da ferramenta "A.5" quanto da "A.7". É importante

\footnotetext{
${ }^{24}$ Por exemplo: “Tome las medidas necesarias para prevenir que estos hechos se repitan en el futuro"(Item 1735, alínea 5, referente ao caso n. 11.506 (Waldemar Gerônimo Pinheiro y José Victor dos Santos x Paraguay).

${ }^{25}$ Nas palavras da Comissão: "Adoptar las medidas legislativas o de otro género que sean necesarias para realizar una investigación exhaustiva e imparcial de las violaciones de derechos humanos cometidas contra el señor Gayle, para identificar, procesar y castigar a todas las personas que sean responsables de esas violaciones de derechos" (CIDH, 2017, item 1521, alínea 2).
} 
destacar também que, nos casos das ferramentas de caráter pecuniário, consideramos somente a sua presença, e não o seu valor ou mesmo o número de beneficiários. ${ }^{26}$

Em seguida, categorizamos cada uma dessas ferramentas que compõem as soluções de casos a partir do seu status de cumprimento. Ressaltamos que essa classificação diz respeito ao status de cumprimento das ferramentas, e não do desenho da solução do caso como um todo (com todas as suas ferramentas analisadas em conjunto). Três são as possibilidades: (i) cumprida, (ii) descumprida e (iii) sem informações sobre o seu cumprimento.

Por fim, elaboramos um índice de cumprimento de cada uma dessas ferramentas, as quais compõem as soluções. Tal índice de efetividade geral diz respeito ao número de cumprimentos de cada uma das ferramentas em face do número de vezes em que foram previstas nos 207 designs de políticas públicas contidos no relatório da CIDH (2017). Optamos por incluir os casos de imprecisão nessa conta, pois eles correspondem às oportunidades em que a ferramenta está prevista no desenho, mas não há informação sobre o seu cumprimento. 0 índice oscila entre 0 e 1 , sendo que, quanto mais se aproxima do zero, menor sua taxa de cumprimento percentual, e quanto mais se aproxima de 1 , maior sua taxa de cumprimento percentual.

A seguinte fórmula foi aplicada para se calcular o índice de efetividade das ferramentas de política pública:

$$
\mathrm{E}: \frac{\mathrm{C}}{\mathrm{C}+\mathrm{D}+\mathrm{I}}
$$

Nessa fórmula, "E" significa o índice de efetividade da ferramenta (que varia entre 0 e 1), a variável " $C$ " representa a quantidade de vezes que a ferramenta foi prevista e cumprida, "D" a quantidade de vezes que a ferramenta foi prevista e descumprida e, "I" é a quantidade de vezes que a ferramenta foi prevista, mas não há dados sobre seu cumprimento (indeterminação).

\footnotetext{
${ }^{26}$ Nossa escolha se deve tanto para manter uma coerência entre as ferramentas utilizadas, como também devido à ausência de informações completas no próprio relatório. Em alguns casos, não há o número preciso de vítimas (e.g., caso n. 11.204, Statehood Solidarity Committee v. Estados Unidos, e caso n. 11.197, Comunidad San Vicente de los Cimientos v. Guatemala). Assim, ao invés de se tentar levar em consideração a quantidade de repetições das ferramentas que envolvem valores financeiros, consideramos somente sua presença no desenho. Por exemplo, havendo o pagamento de uma só indenização (no valor x) ou mesmo vinte indenizações (valor 20x), lançamos apenas a presença da ferramenta, sem dar nenhum peso a ela.
} 
Tabela 1 | Ferramentas de status de cumprimento individual

\begin{tabular}{|c|c|c|c|c|c|c|}
\hline & Descrição & Cump. & Descump. & Imprec. & Total & Índice \\
\hline N.1 & $\begin{array}{l}\text { Publicação do acordo, da } \\
\text { recomendação ou do resultado de } \\
\text { trabalho na imprensa nacional e/ } \\
\text { ou local }\end{array}$ & 17 & 7 & 2 & 26 & 0,6538 \\
\hline N.2 & $\begin{array}{l}\text { Declaração pública em honra } \\
\text { ao nome da vítima e/ou seus } \\
\text { familiares }\end{array}$ & 27 & 7 & 3 & 37 & 0,7297 \\
\hline N.3 & $\begin{array}{l}\text { Reconhecimento da } \\
\text { responsabilidade internacional do } \\
\text { Estado }\end{array}$ & 26 & 6 & 1 & 33 & 0,7878 \\
\hline N.4 & $\begin{array}{l}\text { Adequação de conteúdo em } \\
\text { grades curriculares de cursos de } \\
\text { formação profissional }\end{array}$ & 8 & 3 & 1 & 12 & 0,6666 \\
\hline N.5 & $\begin{array}{l}\text { Promoção da capacitação de } \\
\text { agentes públicos }\end{array}$ & 9 & 6 & 8 & 23 & 0,3913 \\
\hline N.6 & $\begin{array}{l}\text { Produção de informações } \\
\text { (incluindo comissões da verdade) }\end{array}$ & 10 & 9 & 2 & 21 & 0,4761 \\
\hline N.7 & Difusão de informações & 3 & 5 & 2 & 10 & 0,3 \\
\hline A.1 & $\begin{array}{l}\text { Prestação de informações ou } \\
\text { realização de determinados atos } \\
\text { administrativos }\end{array}$ & 13 & 41 & 4 & 58 & 0,2241 \\
\hline A. 2 & $\begin{array}{l}\text { Restrição de recursos judiciais } \\
\text { contra sentenças favoráveis às } \\
\text { vítimas ou arquivamento de } \\
\text { procedimentos que atualmente } \\
\text { tramitam em seu desfavor }\end{array}$ & 3 & 0 & 0 & 3 & 1 \\
\hline A. 3 & $\begin{array}{l}\text { Criação de condições para que } \\
\text { as vítimas interponham recursos } \\
\text { ou ações em face das violações } \\
\text { sofridas }\end{array}$ & 10 & 18 & 4 & 32 & 0,3125 \\
\hline A. 4 & $\begin{array}{l}\text { Admissão ou readmissão de } \\
\text { pessoas em cargos, empregos e } \\
\text { funções }\end{array}$ & 7 & 5 & 0 & 12 & 0,5833 \\
\hline A. 5 & $\begin{array}{l}\text { Prosseguimento ou início de } \\
\text { persecuções penais e punição } \\
\text { aos que deram causa à não- } \\
\text { persecução }\end{array}$ & 8 & 91 & 3 & 102 & 0,0784 \\
\hline A. 6 & $\begin{array}{l}\text { Regulamentação de leis ou } \\
\text { propositura de alterações } \\
\text { administrativas }\end{array}$ & 12 & 55 & 16 & 83 & 0,1445 \\
\hline
\end{tabular}




\begin{tabular}{|c|c|c|c|c|c|c|}
\hline A.7 & $\begin{array}{l}\text { Criação, regulamentação ou } \\
\text { reforma de leis }\end{array}$ & 13 & 61 & 12 & 86 & 0,1511 \\
\hline A. 8 & Alteração de penas & 12 & 9 & 0 & 21 & 0,5714 \\
\hline A.9 & $\begin{array}{l}\text { Abstenção por parte de } \\
\text { instituições internas de medidas } \\
\text { que possam prejudicar as vítimas }\end{array}$ & 1 & 2 & 0 & 3 & 0,3333 \\
\hline A.10 & $\begin{array}{l}\text { Elaboração de políticas públicas } \\
\text { diversas }\end{array}$ & 7 & 47 & 13 & 67 & 0,1044 \\
\hline T.1 & $\begin{array}{l}\text { Pagamento de indenização } \\
\text { imediata às vítimas ou a seus } \\
\text { familiares }\end{array}$ & 88 & 47 & 13 & 148 & 0,5945 \\
\hline T.2 & $\begin{array}{l}\text { Pagamento de indenização em } \\
\text { parcelas às vítimas ou a seus } \\
\text { familiares }\end{array}$ & 2 & 0 & 0 & 2 & 1 \\
\hline T.3 & $\begin{array}{l}\text { Pagamento de pensão por morte } \\
\text { aos representantes ou familiares } \\
\text { das vítimas }\end{array}$ & 2 & 0 & 1 & 3 & 0,6666 \\
\hline T.4 & $\begin{array}{l}\text { Isenção de tributos ou taxas em } \\
\text { face das indenizações pagas }\end{array}$ & 39 & 3 & 1 & 43 & 0,9069 \\
\hline T.5 & $\begin{array}{l}\text { Criação de tribunais ad hoc para } \\
\text { lidar com indenizações }\end{array}$ & 3 & 3 & 0 & 6 & 0,5 \\
\hline T.6 & $\begin{array}{l}\text { Pagamento de haveres oriundos } \\
\text { da violação }\end{array}$ & 9 & 5 & 0 & 14 & 0,6428 \\
\hline T.7 & $\begin{array}{l}\text { Concessão de aposentadorias às } \\
\text { vítimas ou a seus familiares }\end{array}$ & 0 & 0 & 0 & 0 & 0 \\
\hline $\mathrm{T} .8$ & $\begin{array}{l}\text { Concessão de fundos sociais } \\
\text { (educacionais, profissionalizantes, } \\
\text { saúde ou moradia) às vítimas ou a } \\
\text { seus familiares }\end{array}$ & 23 & 21 & 0 & 44 & 0,5227 \\
\hline T.9 & Aplicação de multas & 0 & 0 & 1 & 1 & 0 \\
\hline 0.1 & $\begin{array}{l}\text { Criação de órgãos ou setores de } \\
\text { investigação, monitoramento ou } \\
\text { prevenção de direitos humanos }\end{array}$ & 4 & 4 & 3 & 11 & 0,3636 \\
\hline 0.2 & $\begin{array}{l}\text { Criação de cargos a serem } \\
\text { preenchidos por concurso público }\end{array}$ & 1 & 1 & 0 & 2 & 0,5 \\
\hline 0.3 & $\begin{array}{l}\text { Readequação, fortalecimento } \\
\text { ou reformulação de órgãos, } \\
\text { servidores, instituições e setores }\end{array}$ & 5 & 3 & 4 & 12 & 0,4166 \\
\hline N.R & $\begin{array}{l}\text { Adoção de outras ferramentas a } \\
\text { fim de evitar novas violações de } \\
\text { direitos humanos }\end{array}$ & 1 & 9 & 2 & 12 & 0,0833 \\
\hline
\end{tabular}

Fonte: elaboração própria. 
Podemos tirar algumas conclusões a partir dos dados. Em primeiro lugar, em termos quantitativos, os desenhos das soluções, na Comissão, têm clara preferência por certas ferramentas em detrimento de outras. As ferramentas preferidas são: pagamento de indenizações (ferramenta "T.1", feita 148 vezes), iniciar ou prosseguir com persecução penal ("A.5", 102 vezes), criação, revogação ou reforma de leis ("A.7", 86 vezes), propositura de alterações administrativas processuais ("A.6", 83 vezes) e elaboração de uma política pública ("A.10", 67 vezes). Por outro lado, há ferramentas que aparecem poucas vezes, como aplicação de multas ("T.9", 1 vez), criação de cargos por concursos públicos ("O.2", 2 vezes) e pagamento de pensão por morte ("T.3", 3 vezes). Com a categorização proposta neste artigo, podemos identificar um padrão: dentre as seis ferramentas mais utilizadas pela Comissão, cinco estão dentro da categoria de 'autoridade'.

É notável também que a preferência da Comissão por ferramentas de 'autoridade' não se explica pelo índice de cumprimento das mesmas. Pelo contrário: a correlação entre a preferência de ferramentas pela Comissão e o cumprimento pelos Estados é negativa. Nenhuma das seis ferramentas feitas mais vezes está no rol das mais cumpridas pelos Estados. Mas, mais importante: com exceção da ferramenta de pagamento de indenizações ("T.1", índice de cumprimento de 0,594), as outras mais recomendadas estão entre as oito ferramentas menos cumpridas pelos Estados (são elas: "A.1": 0,224; "A.7": 0,151; “A.6": 0,144; “A.10": 0,104; “A.5": 0,078). Com esses dados, podemos considerar então que os Estados também têm claras preferências em relação ao cumprimento de certas ferramentas e que há elementos convincentes para considerar que a CIDH não leva em conta o índice de cumprimento dos Estados como um critério para decidir quais ferramentas fazer constar em seu desenho de solução.

Fazemos duas observações sobre o índice de cumprimento. Primeiro, é significativa a variação entre as ferramentas que são cumpridas e as que não são cumpridas. Este ponto é importante, pois complexifica os trabalhos que ou descartam a efetividade das soluções de organizações internacionais ou aqueles que as sobrevalorizam. A efetividade das ferramentas inseridas nos desenhos de solução varia em face dos seus tipos. Há ferramentas com índice de cumprimento quase total, como isenção de tributos ou taxas em relação às indenizações (ferramenta "T.4", índice de cumprimento de $0,906)$, e outras que quase sempre são descumpridas, como iniciar ou prosseguir com persecução penal ("A.5"), ignorada 91 vezes das 102 em que foi recomendada. A partir 
de tal variação, é possível afirmar que o tipo de ferramenta impacta no cumprimento ou não por parte dos Estados.

Ainda sobre o índice de cumprimento, a partir do modelo de Hood, temos um direcionamento de qual categoria de ferramentas tem um índice melhor. As sete ferramentas mais cumpridas pertencem a duas categorias, 'tesouro' e 'nodalidade'. São elas as ferramentas "T.4" (índice de cumprimento de 0,906), “N.3” (índice de 0,787), “N.2" (índice de 0,729), “N.4" (índice de 0,666) “N.1" (índice de 0,653), “T.6” (índice de 0,642), e "T.1" (índice de 0,594). ${ }^{27}$ Há certo padrão também em relação às ferramentas menos cumpridas. As ferramentas de 'autoridade' estão dentre as menos cumpridas: principalmente "A.5" (índice de 0,07), “A.10" (0,104), “A.6" (0,144), “A.7" (0,151) e "A.1" (0,224). Em termos gerais, o índice total de cumprimento das ferramentas de 'tesouro' e 'nodalidade' é, respectivamente, 0,636 e 0,616, enquanto que as de 'organização' é 0,4 e de 'autoridade' é $0,184 .{ }^{28}$ Tais números mostram que os Estados mais cumprem as medidas relativas a 'tesouro' e 'nodalidade' do que descumprem. A taxa de cumprimento das ferramentas de 'organização' tem um pouco mais de chance de serem descumpridas, enquanto que as de 'autoridade' têm muitas chances de serem desconsideradas pelos Estados.

\section{Considerações finais}

Neste artigo, analisamos as soluções de caso da Comissão Interamericana de Direitos Humanos, consoante relatório de seguimento de casos de 2017, a partir de um ferramental capaz de expor sua diversidade de forma mais rica e complexa. A pesquisa empírica aponta que: (i) as soluções oriundas da $\mathrm{CIDH}$ denotam certa preferência acerca de determinados tipos de ferramentas, (ii) os Estados cumprem certos tipos de ferramentas em detrimento de outros, e (iii) tais cumprimentos não coincidem com as medidas mais elencadas nos desenhos de soluções de casos, no âmbito da CIDH. Esse

\footnotetext{
${ }^{27}$ É importante ressaltar que desconsideramos aquelas ferramentas com baixo valor estatístico, pois aparecem poucas vezes, como a "A.2" (recomendada 3 vezes) e "T.2" e "T.3" (recomendada 2 vezes cada).

${ }^{28}$ Chegamos a esses resultados empregando a mesma fórmula para o índice geral de efetividade, mas considerando os números de "cumprimento", "descumprimento" e "indeterminação" por cada uma das categorias de "nodalidade", "autoridade", "tesouro" e "organização".
} 
diagnóstico revela as nuances e a pluralidade das soluções travadas na CIDH e como essas são recepcionadas pelos Estados. A partir de tais observações, podemos considerar os desenhos das soluções, na $\mathrm{CIDH}$, não como um bloco monolítico, mas como indicativos de suas preferências por determinadas políticas de implementação de direitos humanos. Finalmente, podemos entendê-la como uma organização que constrói de forma particular suas práticas de autoridade por vieses normativos e de expertise na área.

Afirmar que a Comissão tem preferências por determinadas políticas de implementação de direitos não significa desautorizá-la. A literatura liberal insiste em afastar os direitos humanos da política, como se camuflá-los com matizes de naturalidade, universalidade ou abstração pudesse evitar discussões sobre seus usos. Se o filósofo Jürgen Habermas (1994) estiver correto em não separar direitos humanos do princípio da soberania popular, sua emergência e significado político positivo são associados às experiências locais, por mais universal e abstrata que a linguagem de direitos possa ser. Se direitos humanos são condição para uma prática de política deliberativa, o são quando têm sentido para uma comunidade política. Externa a uma comunidade local, uma instituição internacional tem mais impacto quando se preocupa com os sentidos e os usos feitos de suas decisões no plano local. Mostrar as preferências de uma instituição que constrói e é construída pela linguagem dos direitos humanos como a CIDH pode deslocá-la de um longínquo pedestal apoteótico para um lugar onde se discutem diferentes concepções do que é uma "boa sociedade", ou seja, onde se mostram (e se defendem) preferências políticas.

\section{Referências bibliográficas}

BERNARDI, Bruno Boti. Silence, hindrances and omissions: the Inter-American Commission on Human Rights and the Brazilian military dictatorship. The International Journal of Human Rights, v. 22, n. 2, p. 01-21, 2017.

BRYSK, Alison. The politics of human rights in Argentina: protest, change, and democratization. Stanford: Stanford University Press, 1994.

CALABRIA, Carina. Alterações normativas, transformações sociojurídicas: analisando a eficácia da Corte Interamericana de Direitos Humanos. Revista Direito e Práxis, v. 8, n.2, p. 1286-1355, 2017. 
Comissão Interamericana de DiReitos Humanos(CIDH). Informe Anual 2017. Disponível em: <http://www.oas.org/es/cidh/informes/anuales.asp> Acesso em: 14 jul. 2018.

COLE, Wade M. Sovereignty relinquished? Explaining commitment to the International Human Rights Covenants, 1966-1999. American Sociological Review, v. 70, p. 472-495, 2005.

ConVenção Americana de Direitos Humanos. 22 de novembro de 1969. Disponível em: <https:// www.cidh.oas.org/basicos/portugues/c.convencao_americana.htm> Acesso em: 14 jul. 2018.

DANCY, Geoff; SIKKINK, Kathryn. Ratification and human rights prosecutions: toward a transnational theory of treaty compliance. New York University Journal of International Law and Politics, v. 44, n. 3, p. 751-790, 2012.

DWORKIN, Ronald. Levando os direitos a sério. Trad. Nelson Boeira. 3a ed., São Paulo: WMF, 2011.

ENGSTROM, Par. The Inter-American Human Rights System and US-Latin American relations. In: SCARFI, Juan Pablo; TILLMAN, Andrew (eds.) Cooperation and hegemony in US-Latin American relations: Revisiting the Western Hemisphere Idea. Nova York: Palgrave Macmillan, 2016.

FARISS, Christopher J. The changing standard of accountability and the positive relationship between human rights treaty ratification and compliance. British Journal of Political Science, v. 48, n. 1, p. 239-271, 2018.

Goodman, Ryan. Human rights treaties, invalid reservations, and State consent. American Journal of International Law, v. 96, p. 531-560, 2000.

HABERMAS, Jürgen. Human rights and popular sovereignty: the Liberal and Republican versions. Ratio Juris, v. 7, n. 1, p. 1-13, 1994.

HAFNER-BURTON, Emily M.; TSUTSUIKiyoteru. Human rights in a globalizing world: the paradox of empty promises. American Journal of Sociology, v. 110, p. 1373-1411, 2005.

HAFner-Burton, Emilie M.; TsutsuI, Tsutsui; MeYER, John W. International Human Rights Law and the Politics of Legitimation: Repressive States and Human Rights Treaties. International Sociology, v. 23, p. 115-141, 2008. HATHAWAY, Oona A. Do human rights treaties make a difference? Yale Law Journal, v. 111, n. 8, p. 1935-2042, 2002.

HATHAWAY, Oona. Why do countries commit to human rights treaties? Journal of Conflict Resolution, v. 51, p. 588-621, 2007.

HeYnS, Christof; VILJOEN, Frans. The impact of the United Nations Human Rights Treaties on the domestic level. Human Rights Quarterly, v. 23, p. 483-535, 2001.

HILLEBRECHT, Courtney. Rethinking compliance: the challenges and prospects of measuring compliance with International Human Rights Tribunals. Journal of Human Rights Practice. v. 1, n. 3, p. 362-379, 2009.

HILLEBRECHT, Courtney. The domestic mechanisms of compliance with international human rights law: case studies from the Inter-American Human Rights System. Human Rights Quarterly, v. 34, n. 4, p. 959-985, 2012. 
HooD, Christopher C. The tools of government. Londres: Macmillan Press, 1983.

HOOD, Christopher C.; MARGETTS, Helen Z. The tools of government in the digital age. Nova York: Palgrave Macmillan, 2007.

Howlett, Michael; Ramesh, M.; Perl, Anthony. Política pública: seus ciclos e subsistemas, uma abordagem integral. Rio de Janeiro: Campus/Elsevier, 2013.

MANGABEIRA UNGER, Roberto. Law in modern society: toward a criticism of social theory. Nova York: The Free Press, 1977.

MedinA, Cecilia. The Inter-American Commission on Human Rights and the Inter-American Court of Human Rights: reflections on a joint venture. Human Rights Quarterly, v. 12, n. 4, p. 439-464, 1990.

Mutua, Makau. Human Rights: a political and cultural critique. Philadelphia: University of Pennsylvania Press, 2002.

RISSE, Thomas; ROPP, Stephen C.; SIKKINK, Kathryn. The persistent power of human rights: from commitment to compliance. Nova York: CUP, 2014.

SIMMONS, Beth A. Mobilizing for human rights: international law in domestic politics. Nova York: CUP, 2009.

YAMATO, Roberto V. Relendo a construção (negativa) dos direitos humanos internacionais. Carta Internacional, v. 9, n. 2, p. 3-30, 2014.

\section{Adriano Sousa Costa}

(D) https://orcid.org/0000-0002-4554-1009

Bacharel em Direito pelo Centro Universitário de Brasília, Mestre em Ciência Política pela Universidade Federal de Goiás e Doutorando em Ciência Política na Universidade de Brasília. É Delegado de Classe Especial na Polícia Civil do Estado de Goiás, Diretor Jurídico da Associação Nacional de Delegados de Polícia Judiciária, Diretor Jurídico da Federação Nacional de Delegados de Polícia e, atualmente, preside o Sindicato dos Delegados de Polícia do Estado de Goiás. Professor, autor de várias obras jurídicas e membro da Academia Goiana de Direito.

E-mail: praticapolicial@gmail.com

\section{João Roriz}

(D) https://orcid.org/0000-0001-8234-9342

Professor de Relações Internacionais, Faculdade de Ciências Sociais, Universidade Federal de Goiás.

E-mail: joaororiz@ufg.br 